\title{
Redução na população de plantas de soja e o retorno econômico na produção de grãos
}

\section{Reducing soybean plant population and effects on grain net economic return}

\author{
Gisele Herbst VAZQUEZ $^{1 ; 2}$; Amanda Ribeiro PERES ${ }^{3}$; Maria Aparecida Anselmo TARSITANO ${ }^{4}$ \\ ${ }_{2}^{1}$ Parte da tese de doutorado da primeira autora. \\ ${ }^{2}$ Autora para correspondência: Engenheira-Agrônoma, Doutora, Professora. Departamento de Fitotecnia, \\ Tecnologia de Alimentos e Sócio Economia - Universidade Estadual Paulista "Júlio de Mesquita Filho" - \\ Faculdade de Engenharia de Ilha Solteira, SP. Av. Brasil, 56 - Centro e Universidade Camilo Castelo Branco, \\ Fernandópolis, SP. gisele@agr.feis.unesp.br \\ ${ }^{3}$ Engenheira-Agrônoma, Mestranda em Agronomia. Universidade Estadual Paulista "Júlio de Mesquita Filho" - \\ Faculdade de Engenharia de Ilha Solteira. amandarperes_agro@yahoo.com.br \\ ${ }^{4}$ Engenheira-Agrônoma, Doutora, Professora. Universidade Estadual Paulista "Júlio de Mesquita Filho" - \\ Faculdade de Engenharia de Ilha Solteira.maat@agr.feis.unesp.br
}

Recebido em: 08-11-2013; Aceito em: 18-02-2014

\begin{abstract}
Resumo
Frequentemente, no campo, ocorrem reduções na população de plantas devido ao desempenho germinativo inadequado de sementes submetidas a condições adversas e que, nem sempre, são devidamente aquilatadas pelos agricultores. O objetivo desse trabalho foi avaliar os efeitos de reduções na população de plantas de soja resultantes tanto de desempenhos germinativos menores ao esperado, quanto da opção do agricultor pelo uso de populações menores que 400.000 plantas ha $^{-1}$ ( $\mathrm{pl} \mathrm{ha}^{-1}$ ) no momento da semeadura, sobre a produtividade de dois cultivares em áreas com e sem controle químico de plantas daninhas e o retorno econômico da produção de grãos em Jaboticabal/SP. O delineamento experimental adotado foi o de blocos ao acaso, em esquema fatorial $5 \times 2 \times 2$, sendo cinco populações de plantas (400.000; 340.000; 280.000; 220.000 e $160.000 \mathrm{pl} \mathrm{ha}^{-1}$ ), dois manejos de plantas daninhas (com e sem controle químico) e duas cultivares (BRSMG 68 Vencedora e MSOY 8001), com quatro repetições. A produtividade de grãos, independentemente da cultivar, cresceu de forma linear com o aumento da população. A cultivar BRSMG 68 Vencedora mostrou-se mais produtiva do que a cultivar M-SOY 8001 . A produtividade de grãos com manejo de plantas daninhas com herbicida foi maior do que sem manejo. A maximização do retorno econômico líquido, contudo, só aconteceu com a população de $400.000 \mathrm{pl} \mathrm{ha}^{-1}$, independentemente da cultivar e do manejo de plantas daninhas adotado. A cultivar BRSMG 68 Vencedora, de crescimento vegetativo vigoroso, permitiu a maximização do retorno econômico quando não se efetuou o controle químico das plantas daninhas.
\end{abstract}

Palavras-chave adicionais: análise econômica; custo de produção; estande; Glycine max.

\begin{abstract}
Frequently plant population in the field is reduced due to the seeds inadequate germination performance when submitted to adverse environmental conditions. The objective of this study was to evaluate the effects of reductions in soybean plant population resulting both from field germination performance below the expected as from a conscious decision of the farmer of using plant populations lower than 400,000 plants ha $^{-1}$ on plant productivity of two soybean cultivars with and without chemical control of weeds and on the economical return of grain yield. The treatments consisted of the combination of five plant populations $\left(400,000,340,000,280,000,220,000\right.$, and 160,000 plants ha $\left.{ }^{-1}\right)$, two weed plants management (with and without chemical control), and two cultivars, that is, 'BRSMG 68 Vencedora' and 'MSOY 8001'. The experimental units were distributed in the field according to a randomized complete block design, with four repetitions. Grain yield increased linearly with increasing plant population in both cultivars. Cultivar 'BRSMG 68 Vencedora' was more productive than cultivar 'MSOY 8001'. The chemical control of weeds resulted in increased grain yield in both cultivars. The net economical return was maximized only when plant population was of 400,000 plants ha $^{-1}$, independently of cultivar and weed plants management. The maximization of the economical return of variety 'BRSMG 68 Vencedora', due to its vigorous vegetative growth, was verified to occur even when the weeds were not chemically controlled.
\end{abstract}

Additional keywords: economical analysis; Glycine max; production cost; stand. 


\section{Introdução}

Nas últimas décadas, a produção mundial de grãos de soja (Glycine max L.) cresceu, bem como o consumo, impulsionada por constantes incorporações tecnológicas que levaram a ganhos de produtividade. A pesquisa contribuiu fortemente para esse desempenho com fluxos contínuos de inovações tecnológicas que procuraram atender, inicialmente, às demandas de caráter técnico-agronômico (SOUZA, 2013). Atualmente, com o acirramento da competição num mercado globalizado, análises de custos e rentabilidade passam a ser igualmente importantes para a avaliação e a adoção de novas alternativas.

Nos últimos anos, o melhoramento genético da soja, devido a fatores negativos, como o aumento de doenças foliares e vasculares, foi direcionado para obtenção de cultivares que permitissem a diminuição da população de plantas por área. A tendência é a de redução na densidade de semeadura, usando-se em torno de 10 a 15 plantas por metro, pois, além de não afetar a produtividade, proporciona decréscimos no custo de produção pela redução no gasto com sementes (TOURINO et al., 2002).

Até a década de 1980, era comum cultivar soja com 400.000 plantas ha $^{-1}\left(\mathrm{pl} \mathrm{ha}^{-1}\right)$ ou até mais, com o intuito de que a maior população de plantas garantisse maior competição entre as plantas e, consequentemente, aumentasse a altura e sombreasse o solo mais rápida e uniformemente, de forma a competir com as plantas daninhas. Entretanto, com o surgimento dos herbicidas de pós-emergência, essa razão perdeu importância. No entanto, nos dias atuais, o desenvolvimento de cultivares de maior porte e a melhoria na capacidade produtiva do solo contribuíram para a redução da população de plantas, permitindo utilizar $300.000 \mathrm{pl} \mathrm{ha}^{-1} \mathrm{e}$, em condições favoráveis ao acamamento das plantas, de 200.000 a $250.000 \mathrm{pl} \mathrm{ha}^{-1}$ (EMBRAPA, 2011). De acordo com FRANÇA-NETO et al. (2010), as cultivares modernas de soja possuem alta produtividade, em baixas populações, com 180.000 a $250.000 \mathrm{pl} \mathrm{ha}^{-1}$.

Todavia, frequentemente, ocorrem reduções na população de plantas em virtude de um desempenho germinativo inadequado de sementes submetidas a condições adversas e que, muitas vezes, não são devidamente aquilatadas pelos agricultores. A não percepção de reduções na população de plantas pelo agricultor ocorre em virtude de que essas variações pouco afetam a produtividade da soja, já que ela é capaz de se adaptar de maneira eficiente aos espaços disponíveis (capacidade de compensação) através de modificações em sua morfologia e em seus componentes da produtividade.
Assim, o objetivo deste trabalho foi o de avaliar os efeitos de reduções na população de plantas de soja resultantes tanto de desempenhos germinativos menores do esperado, quanto da opção espontânea do agricultor pelo uso de populações menores que $400.000 \mathrm{pl} \mathrm{ha}^{-1}$ no momento da semeadura, sobre a produtividade de duas cultivares desenvolvidas em áreas com e sem controle de plantas daninhas e o retorno econômico da produção de grãos.

\section{Material e métodos}

O experimento foi realizado no período de 19-11-2002 a 26-03-2003, na área experimental da UNESP, em Jaboticabal-SP, a qual está localizada na latitude de $21^{\circ} 14^{\prime} 05^{\prime}$ S, longitude 48¹7'09" W e altitude média de 613,68 m. O clima da região, segundo a classificação internacional de Köeppen, é do tipo Cwa, isto é, mesotérmico de inverno seco, sendo a temperatura média anual de $22,2{ }^{\circ} \mathrm{C}$. A precipitação total anual é de 1.424,6 mm, a evapotranspiração real anual de $1.025 \mathrm{~mm}$ e a umidade relativa média anual de $70,8 \%$.

O solo foi classificado como Latossolo Vermelho eutrófico típico de textura argilosa, e a análise do solo, na camada de 0 a $20 \mathrm{~cm}$ de profundidade, revelou os seguintes resultados: $\mathrm{pH}\left(\mathrm{CaCl}_{2}\right)=5,2 ; \mathrm{M} . \mathrm{O} .=25 \mathrm{~g} \mathrm{dm}^{-3} ; \mathrm{P}$ (resina) $=$ $43 \mathrm{mg} \mathrm{dm}{ }^{-3} ; \mathrm{K}, \mathrm{Ca}, \mathrm{Mg}, \mathrm{H}+\mathrm{Al}, \mathrm{SB}$, e CTC=4,6; 33; $12 ; 34 ; 49,6$ e $83,6 \mathrm{mmol}_{\mathrm{c}} \mathrm{dm}^{-3}$, respectivamente, e $\mathrm{V}=59 \%$. Não foi realizada a calagem, e a adubação foi efetuada com o equivalente a $40 \mathrm{~kg} \mathrm{ha}^{-1}$ de $\mathrm{P}_{2} \mathrm{O}_{5}$ e $40 \mathrm{~kg} \mathrm{ha}^{-1}$ de $\mathrm{K}_{2} \mathrm{O}$, de acordo com a análise de solo.

O delineamento experimental adotado foi o de blocos ao acaso, em esquema fatorial $5 \times 2 \times 2$, sendo cinco populações de plantas (400.000; 340.000; 280.000; 220.000 e $160.000 \mathrm{pl} \mathrm{ha}^{-1}$ ), dois manejos de plantas daninhas (com e sem o controle químico) e duas cultivares de soja (BRSMG 68 Vencedora e M-SOY 8001 ), com quatro repetições. As parcelas foram compostas por quatro linhas de $5 \mathrm{~m}$, com espaçamento entre linhas de $0,43 \mathrm{~m}$, e a área útil foi constituída pelas duas fileiras centrais, desprezando-se 0,50 $\mathrm{m}$ de ambas as extremidades.

As cultivares BRSMG 68 Vencedora e a M-SOY 8001 apresentam hábito de crescimento determinado e são semiprecoces, com ciclo de 118 a 125 dias.

O preparo do solo foi o convencional, e a semeadura, realizada manualmente com sementes tratadas com fungicida (carboxin-20\% + thiram-20\% na dose de $50+50 \mathrm{~g}$ do ingrediente ativo (i.a.) por $100 \mathrm{~kg}$ de semente) e inoculadas com Bradyrhizobium spp., em quantidade $40 \%$ superior à necessária, para estabelecer a densidade desejada. Nas parcelas com controle 
de plantas daninhas, foi efetuada a pulverização manual do herbicida trifluralin, na dose de $2,1 \mathrm{~kg} \mathrm{ha}^{-1}$ do i.a. em pré-emergência. Vinte e quatro dias após a emergência, todas as parcelas foram desbastadas. Não se procurou a equidistância entre as plantas, apenas mensurou-se o número inicial de plantas na linha, eliminando-se as que excediam o valor desejado. Um mês após a semeadura (estádio $\mathrm{V}_{4}-\mathrm{V}_{5}$ ), todas as parcelas com controle de plantas daninhas foram pulverizadas, utilizando equipamento costal, com o herbicida fomesafen + fluazifop-p-butil, na dose de $0,20+0,25 \mathrm{~kg} \mathrm{ha}^{-1}$ do i.a., não havendo necessidade de novas aplicações.

O controle de percevejos foi realizado com quatro aplicações de inseticidas, sendo duas aplicações com deltametrina $\left(7,5 \mathrm{~g} \mathrm{ha}^{-1}\right.$ do i.a.) e duas com endosulfan (437,5 $\mathrm{g} \mathrm{ha}^{-1}$ do i.a.). Não ocorreram problemas com doenças.

Ao atingir o ponto de colheita, as plantas da área útil das parcelas foram trilhadas mecanicamente. Em seguida, as sementes foram pesadas para a determinação da produtividade em $\mathrm{kg} \mathrm{ha}^{-1}$ corrigida para $13 \%$ de teor de água (b.u.).

A análise estatística dos dados foi realizada, utilizando-se do programa SISVAR 5.3 (FERREIRA, 2011). Como o fator população é quantitativo, procedeu-se à análise de variância pelo teste $\mathrm{F}$ e, quando significativo, realizou-se a análise de regressão. Já os fatores cultivar e manejo de plantas daninhas, por serem qualitativos, foram submetidos à análise de variância, pelo teste $\mathrm{F}$; e as médias, comparadas pelo teste de Tukey, em nível de 5\% de probabilidade de erro.

A análise benefício-custo foi a ferramenta econômica utilizada para avaliar o impacto da redução da população de plantas e do manejo das plantas daninhas na rentabilidade da atividade soja. Nessa análise, o benefício refere-se às receitas, e o custo, aos desembolsos e compensações econômicas decorrentes do uso de recursos produtivos para gerar receitas. O maior saldo positivo entre receitas e custos indica o resultado a ser adotado por expressar o melhor benefício líquido no aspecto monetário.

A análise econômica foi desenvolvida comparando-se o retorno econômico líquido (REL) de cada população de plantas na cultivar e no mesmo manejo de plantas daninhas, bem como entre cultivares e entre manejos. Também, por meio do cálculo da variação percentual do REL, foram avaliados os ganhos ou perdas econômicas decorrentes da variação da população de plantas na cultivar. Adicionalmente, os melhores resultados econômicos de cada cultivar e o tipo de manejo das plantas daninhas foram comparados e determinados os benefícios e custos.

As receitas brutas da soja foram determinadas com base em três valores: no preço de maio de 2012 do Instituto de Economia Agrícola
(IEA, 2012); da média dos meses de maio dos últimos cinco anos (2008-2012) do IEA, e do preço mínimo da saca de $60 \mathrm{~kg}$ em maio de 2012, em todo o território nacional (exceto MT, RO, AM, PA e AC), da Companhia Nacional de Abastecimento (CONAB, 2012), e na produtividade atingida na área experimental para cada fator estudado.

$\mathrm{Na}$ análise de custo, foram consideradas duas situações para avaliar as variações da população de plantas: uma em consequência do efeito de fatores ambientais adversos sobre uma mesma quantidade inicial de sementes (Adversidade), e outra resultante da opção do agricultor por populações menores que $400.000 \mathrm{pl} \mathrm{ha}^{-1}$, o que o levaria a empregar menos sementes para a semeadura (redução programada). Em ambos os casos, a metodologia de determinação dos custos de produção foi a mesma.

Os custos de produção de soja foram estimados utilizando-se da estrutura de Custo Operacional Total (COT) do Instituto de Economia Agrícola - IEA/SP, proposta por MARTIN et al. (1998). O COT compõe-se de todos os custos variáveis e alguns custos fixos (depreciação dos bens duráveis, valor da mão de obra familiar indispensável à produção, além de impostos e taxas). Na estrutura do COT, assume-se que a remuneração da terra, do empresário e do capital (ativo permanente), que integram o custo fixo da estrutura do custo total de produção, ocorre por meio de um resíduo, que resulta da diferença entre o valor da receita bruta (RB) e o COT. Na determinação do COT, os coeficientes técnicos relativos aos serviços mecanizados e manuais de produção, e aos insumos das operações de calagem e controle da ferrugem (calcário e fungicida não foram utilizados neste experimento, mas são comumente empregados pelos produtores da região) foram obtidos da Cooperativa dos Agricultores da Região de Orlândia - CAROLSP. Os coeficientes técnicos das aplicações de defensivos e da colheita foram mantidos constantes nas diferentes populações, pois a velocidade de deslocamento da máquina, em cada operação, independe do número de plantas por área.

Os insumos componentes dos custos de produção foram os utilizados na área experimental, acrescidos de duas aplicações do fungicida tebuconazol, na dose de $100 \mathrm{~g} \mathrm{ha}^{-1}+$ espaIhante adesivo, utilizados no controle de ferrugem-asiática, apesar de essa não ter sido detectada neste experimento. A quantidade de sementes de cada cultivar foi determinada com base no valor cultural (VC) apresentado. As doses de fungicida e de inoculante aplicadas na semeadura variaram em função da quantidade de sementes empregada em cada cultivar.

As quantidades de adubos, herbicidas, inseticidas, fungicidas e espalhante adesivo aplicadas não sofreram alterações, visto que seus 
cálculos dependem apenas da área a ser tratada e não da população. O número de aplicações de herbicidas também não variou, já que a soja foi capaz de preencher rapidamente todos os espaços disponíveis de forma a impedir o desenvolvimento de plantas daninhas.

Os custo/hora das máquinas e implementos, empregados no cálculo das operações mecanizadas, foram obtidos junto ao IEA-SP relativo ao mês de agosto de 2012, que é a mesma fonte utilizada pela CAROL em suas planilhas de custo de produção. Estes custos são compostos dos itens: combustível, lubrificantes, reparos de manutenção, seguro, garagem e depreciação. Os preços dos insumos foram obtidos no IEA, correspondente ao mês de agosto de 2012. Todos os preços utilizados nas estimativas dos custos limitaram-se à safra de 2012.

Além dos custos das operações e dos gastos com os insumos, que correspondem ao COE (Custo Operacional Efetivo), integraram o COT despesas relativas à pós-colheita, que são o transporte até o armazém, recebimento, limpeza, beneficiamento e armazenamento, além de outras despesas que correspondem a $5 \%$ do COE.

Tanto na Adversidade, quanto na Redução programada, realizou-se uma análise comparativa dos resultados econômicos obtidos nas seguintes opções:

- cV. BRSMG 68 Vencedora x M-SOY 8001 nos melhores retornos econômicos, com uso de herbicidas;

- cv. BRSMG 68 Vencedora x M-SOY 8001 nos melhores retornos econômicos, sem controle de plantas daninhas;

- controle com herbicidas x sem controle de plantas daninhas nos melhores retornos econômicos de cada cultivar; e

- os dois melhores resultados econômicos de cada cultivar.

Essas melhores opções tiveram, como variável de decisão, a cultivar ou o manejo das plantas daninhas, e tanto os benefícios como os custos que foram comparados para dimensionar o ganho ou a perda econômica.

\section{Resultados e discussão}

Houve diferença significativa para os fatores população, cultivares e manejo de plantas daninhas para produtividade de grãos. No entanto, as interações entre esses fatores (população x cultivares, população x manejo, cultivares $x$ manejo, população $x$ cultivares $x$ manejo) não foram significativas, demonstrando não haver relação entre elas (Tabela 1).

A produtividade de grãos da soja, independentemente da cultivar, obteve efeito linear crescente com o aumento da população (Tabela 1). De maneira geral, observou-se que a produtivi- dade de grãos obtida na maior população $\left(400.000 \mathrm{pl} \mathrm{ha}^{-1}\right)$ foi de $4.651 \mathrm{~kg} \mathrm{ha}^{-1}$, enquanto na menor população (160.000 pl ha-1) foi de $4.033 \mathrm{~kg}$ $\mathrm{ha}^{-1}$, uma diferença de $618 \mathrm{~kg} \mathrm{ha}^{-1}$, ou seja, uma redução de $13,28 \%$ ao se passar da maior para a menor população de plantas.

Sabe-se que, em regiões com altitudes inferiores a $800 \mathrm{~m}$ e de clima mais quente, a soja possui limitação de altura de planta; assim, populações em torno de $400.000 \mathrm{pl} \mathrm{ha}^{-1}$ podem contribuir para aumentar o porte das plantas e 0 fechamento mais rápido das entrelinhas, resultando em maiores produtividades (EMBRAPA, 2010; EMBRAPA, 2011). No caso deste experimento, a área localizava-se a $613 \mathrm{~m}$ de altitude e no município de Jaboticabal, que possui temperatura média dos meses mais quentes igual a $24,3^{\circ} \mathrm{C}$ (janeiro e fevereiro), a do mês mais frio igual a $18,6^{\circ} \mathrm{C}$ (junho) e a média anual de $22,2^{\circ} \mathrm{C}$, o que, provavelmente, contribuiu para um menor desenvolvimento das plantas, contribuindo dessa forma para que as maiores produtividades fossem obtidas com a maior população.

Da mesma forma, REZENDE et al. (2004), em Jussara-GO (317 m de altitude), ao avaliarem o efeito da população de plantas (200.000; 300.000; 400.000; 500.000; 600.000 e $700.000 \mathrm{pl} \mathrm{ha}^{-1}$ ) sobre a produtividade de grãos de soja, também verificaram que a população de plantas altera significativamente o rendimento de grãos, com destaque para as maiores populações $\left(400.000 ; 600.000\right.$ e $\left.700.000 \mathrm{pl} \mathrm{ha}^{-1}\right)$, concluindo que a melhor opção seria a de usar $400.000 \mathrm{pl} \mathrm{ha}^{-1}$, pois, além de proporcionar menor gasto de sementes, foi a que teve o menor índice de acamamento. Por outro lado, ANDRADE et al. (2010), avaliando 15 genótipos de soja nas populações de 250.000; 300.000; 350.000 e $400.000 \mathrm{pl} \mathrm{ha}^{-1}$ e em quatro épocas de semeadura em Uberlândia-MG (altitude de $872 \mathrm{~m}$ ), concluíram que as populações de plantas de 250.000 e $300.000 \mathrm{pl} \mathrm{ha}^{-1}$ tiveram maiores produtividades para a maioria dos genótipos avaliados. TOURINO et al. (2002), em LavrasMG (altitude de $918 \mathrm{~m}$ ), relataram aumento na produtividade da soja no espaçamento de $45 \mathrm{~cm}$, com a redução da densidade para 10 plantas $\mathrm{m}^{-1}$ (estande de $222.222 \mathrm{pl} \mathrm{ha}^{-1}$ ) e que, nas menores densidades, as plantas são mais baixas, acamam menos e têm maior porcentagem de sobrevivência.

A cultivar BRSMG 68 Vencedora obteve maior produtividade do que a cultivar M-SOY 8001, diferindo estatisticamente e produzindo $23,3 \%$ ou $883 \mathrm{~kg} \mathrm{ha}^{-1}$ a mais de grãos (Tabela 1 ).

Por sua vez, o manejo de plantas daninhas com herbicida aumentou a produtividade de grãos em 13,4\% (533 kg ha ${ }^{-1}$ ) em relação ao sem aplicação de herbicida, ressaltando a importância do controle das plantas daninhas 
(Tabela 1). MELO et al. (2001), semeando soja no espaçamento de $60 \mathrm{~cm}$, e TIMOSSI \& DURIGAN (2002), no espaçamento de $45 \mathrm{~cm}$, observaram reduções de $32,6 \%$ e de $26 \%$, respectivamente, na produtividade da soja quando houve convivência soja-planta daninha, em comparação ao tratamento com controle.

Os valores do COT para as cultivares BRS MG 68 Vencedora e MS 8001 estão nas Tabelas 2 e 3, respectivamente, e diferiram nas diversas populações, manejos e cultivares estudados em relação aos itens operação de semeadura e despesas pós-colheita e outras despesas, principalmente na situação de redução programada.

A quantidade de sementes utilizada para cada população de plantas foi obtida com base no valor cultural original. Na situação de Redução programada, para as populações de 400.000; 340.000; 280.000; 220.000 e $160.000 \mathrm{pl} \mathrm{ha}^{-1}$, foram calculadas, respectiva- mente, as quantidades de sementes e os custos da operação de semeadura mais insumos (fungicida e inoculante) por hectare de $74,1 \mathrm{~kg}$ e $\mathrm{R} \$$ 264,$2 ; 63,0 \mathrm{~kg}$ e $\mathrm{R} \$ 238,9 ; 51,9 \mathrm{~kg}$ e $\mathrm{R} \$ 212,9$; $40,8 \mathrm{~kg}$ e $\mathrm{R} \$ 186,9$ e $29,7 \mathrm{~kg}$ e $\mathrm{R} \$ 161,5$ para cv. BRSMG 68 Vencedora e de 53,7 kg e $R \$ 217,1$; $45,7 \mathrm{~kg}$ e $\mathrm{R} \$ 198,5 ; 37,6 \mathrm{~kg}$ e $\mathrm{R} \$ 179,9 ; 29,6 \mathrm{~kg}$ e $R \$ 161,3$ e $21,5 \mathrm{~kg}$ e $\mathrm{R} \$ 142,6$ para a M-SOY 8001. Já na situação Adversidade, em todas as populações, utilizou-se de 74,1 kg e R\$264,2 para a cV. BRSMG 68 Vencedora e de 53,7 kg e $\mathrm{R} \$ 217,1$ para a cv. M-SOY 8001.

$O$ custo por saca (COT) em $R \$ s c^{-1}$ foi menor na cV. BRSMG 68 Vencedora do que na cv. M-SOY 8001. O menor custo médio de produção por saca foi obtido com a cv. BRSMG 68 Vencedora, na população de $400.000 \mathrm{pl} \mathrm{ha}^{-1} \mathrm{e}$ sem o controle de daninhas $\left(\mathrm{R} \$ 20,8 \mathrm{sc}^{-1}\right)$, nas duas situações estudadas (Adversidade e Redução programada).

Tabela 1 - Produtividades de grãos de soja e resumo da análise da variância em função da população de plantas, cultivares e manejo de plantas daninhas. Jaboticabal-SP. Soybean grains yield and summary of analysis of variance as a function of plant population, cultivar and weed management. Jaboticabal/SP.

\begin{tabular}{|c|c|}
\hline Tratamentos & Produtividade $\left(\mathrm{kg} \mathrm{ha}^{-1}\right)$ \\
\hline \multicolumn{2}{|c|}{ População (pl ha ${ }^{-1}$ ) } \\
\hline 160.000 & (1) 4.033 \\
\hline 220.000 & 3.985 \\
\hline 280.000 & 4.334 \\
\hline 340.000 & 4.185 \\
\hline 400.000 & 4.651 \\
\hline \multicolumn{2}{|c|}{ Cultivar } \\
\hline BRSMG 68 Vencedora & ${ }^{(2)} 4.679 a$ \\
\hline M-SOY 8001 & $3.796 b$ \\
\hline \multicolumn{2}{|c|}{ Manejo de plantas daninhas } \\
\hline Com Herbicida & $4.504 a$ \\
\hline Sem Herbicida & $3.971 b$ \\
\hline \multicolumn{2}{|c|}{ Teste F } \\
\hline População & $5,871^{* *}$ \\
\hline Cultivares & $79,358^{* *}$ \\
\hline Manejo de plantas daninhas & $28,966^{\star *}$ \\
\hline População x Cultivares & $0,170^{\mathrm{ns}}$ \\
\hline População x Manejo & $0,784^{\mathrm{ns}}$ \\
\hline Cultivares $\times$ Manejo & $1,174^{\mathrm{ns}}$ \\
\hline $\begin{array}{c}\text { População x Cultivares x Manejo } \\
\text { DMS Cultivar }\end{array}$ & $=-\frac{0,729^{\mathrm{ns}}}{4.237,60}-\ldots$ \\
\hline DMS Manejo & 198 \\
\hline CV (\%) & 10,46 \\
\hline
\end{tabular}


Tabela 2 - Produtividade de grãos, preço real (PR), receita bruta (RB), custo operacional total (COT), retorno econômico líquido (REL) e variação percentual (V) da soja cultivar BRSMG 68 Vencedora em função da população de plantas com o uso de herbicidas (A) e sem o controle de plantas daninhas (B) Jaboticabal-SP. Dados econômicos de 2012. Grain yield, real price (PR), gross revenue (RB), total operating cost (TOC), net economic returns (REL) and percentage variation (V) of soybean BRSMG 68 Vencedora cultivar according to the plant population using herbicides $(A)$ and without weed control (B). Jaboticabal / SP. Economic data of 2012.

\begin{tabular}{|c|c|c|c|c|c|c|c|c|c|c|c|c|}
\hline \multirow{2}{*}{ População } & \multirow{2}{*}{\multicolumn{2}{|c|}{$\frac{\text { Produtividade }}{\left(\mathrm{kg} \mathrm{ha}^{-1}\right)\left(\mathrm{sc} \mathrm{ha}^{-1}\right)}$}} & \multirow{2}{*}{$\frac{\mathrm{PR}}{\left(\mathrm{R} \$ \mathrm{sc}^{-1}\right)}$} & \multirow{2}{*}{$\begin{array}{c}\mathrm{RB} \\
\left(\mathrm{R} \$ \mathrm{ha}^{-1}\right) \\
\end{array}$} & \multicolumn{2}{|c|}{${ }^{1} \mathrm{COT}$} & \multicolumn{2}{|c|}{${ }^{2} \mathrm{COT}$} & \multirow{2}{*}{\multicolumn{2}{|c|}{$\begin{array}{c}{ }^{1} \mathrm{REL} \quad{ }^{2} \mathrm{REL} \\
\left(\mathrm{R} \$ \mathrm{ha}^{-1}\right) \\
\end{array}$}} & \multirow{2}{*}{$\begin{array}{r}{ }^{1,3} \mathrm{~V} \\
\end{array}$} & \multirow{2}{*}{$\frac{{ }^{2,3} \mathrm{~V}}{6)}$} \\
\hline & & & & & $\left(\mathrm{R} \$ \mathrm{ha}^{-1}\right)$ & $\left(\mathrm{R} \$ \mathrm{sc} \mathrm{c}^{-1}\right)$ & $\left(\mathrm{R} \$ \mathrm{~h}^{-1}\right)$ & $\left(\mathrm{R} \$ \mathrm{sc}^{-1}\right)$ & & & & \\
\hline \multicolumn{13}{|c|}{ (A) BRSMG 68 Vencedora - Com uso de herbicidas } \\
\hline \multirow{3}{*}{400.000} & & & $54,5^{*}$ & $4.798,3$ & $1.982,2$ & 22,5 & $1.982,2$ & 22,5 & $2.816,1$ & $2.816,1$ & 0,0 & 0,0 \\
\hline & 5.286 & 88,1 & $43,6^{* *}$ & $3.836,3$ & $1.982,2$ & 22,5 & $1.982,2$ & 22,5 & $1.854,2$ & $1.854,2$ & 0,0 & 0,0 \\
\hline & & & $26,1^{* * *}$ & $2.300,0$ & $1.982,2$ & 22,5 & $1.982,2$ & 22,5 & 317,9 & 317,9 & 0,0 & 0,0 \\
\hline \multirow{3}{*}{340.000} & & & 54,5 & $4.323,3$ & $1.964,4$ & 24,8 & $1.937,9$ & 24,4 & $2.358,9$ & $2.385,4$ & $-16,2$ & $-15,3$ \\
\hline & 4.762 & 79,4 & 43,6 & $3.456,6$ & $1.964,4$ & 24,8 & $1.937,9$ & 24,4 & $1.492,1$ & $1.518,7$ & $-19,5$ & $-18,1$ \\
\hline & & & 26,1 & $2.072,4$ & $1.964,4$ & 24,8 & $1.937,9$ & 24,4 & 107,9 & 134,4 & $-66,0$ & $-57,7$ \\
\hline \multirow{3}{*}{280.000} & & & 54,5 & $4.622,9$ & $1.975,5$ & 23,3 & $1.921,7$ & 22,6 & $2.647,4$ & $2.701,2$ & $-6,0$ & $-4,1$ \\
\hline & 5.092 & 84,9 & 43,6 & $3.696,1$ & $1.975,5$ & 23,3 & $1.921,7$ & 22,6 & $1.720,6$ & $1.774,4$ & $-7,2$ & $-4,3$ \\
\hline & & & 26,1 & $2.216,0$ & $1.975,5$ & 23,3 & $1.921,7$ & 22,6 & 240,5 & 294,3 & $-24,3$ & $-7,4$ \\
\hline \multirow{3}{*}{220.000} & & & 54,5 & $4.466,0$ & $1.969,8$ & 24,0 & $1.888,7$ & 23,0 & $2.496,2$ & $2.577,3$ & $-11,4$ & $-11,4$ \\
\hline & 4.919 & 82,0 & 43,6 & $3.570,7$ & $1.969,8$ & 24,0 & $1.888,7$ & 23,0 & $1.600,9$ & $1.682,0$ & $-13,7$ & $-9,3$ \\
\hline & & & 26,1 & $2.140,8$ & $1.969,8$ & 24,0 & $1.888,7$ & 23,0 & 171,0 & 252,1 & $-46,2$ & $-20,7$ \\
\hline \multirow{3}{*}{160.000} & & & 54,5 & $4.484,0$ & $1.970,5$ & 23,9 & $1.862,6$ & 22,6 & $2.513,5$ & $2.621,4$ & $-10,7$ & $-6,9$ \\
\hline & 4.939 & 82,3 & 43,6 & 3585,0 & 1970,5 & 23,9 & $1.862,6$ & 22,6 & $1.614,6$ & $1.722,4$ & $-12,9$ & $-7,1$ \\
\hline & & & 26,1 & $2.149,4$ & $1.970,5$ & 23,9 & $1.862,6$ & 22,6 & 178,9 & 286,8 & $-43,7$ & $-9,8$ \\
\hline \multicolumn{13}{|c|}{ (B) BRSMG 68 Vencedora - Sem controle de plantas daninhas } \\
\hline \multirow{3}{*}{400.000} & & & & $4.536,3$ & $1.734,0$ & 20,8 & $1.734,0$ & 20,8 & $2.802,2$ & $2.802,2$ & 0,0 & 0,0 \\
\hline & 4.997 & 83,3 & 43,6 & $3.626,8$ & $1.734,0$ & 20,8 & $1.734,0$ & 20,8 & $1.892,8$ & $1.892,8$ & 0,0 & 0,0 \\
\hline & & & 26,1 & $2.174,4$ & $1.734,0$ & 20,8 & $1.734,0$ & 20,8 & 440,4 & 440,4 & 0,0 & 0,0 \\
\hline \multirow{3}{*}{340.000} & & & 54,5 & $4.008,5$ & $1.714,7$ & 23,3 & $1.688,2$ & 22,9 & $2.293,7$ & $2.320,2$ & $-18,2$ & $-17,2$ \\
\hline & 4.416 & 73,6 & 43,6 & $3.204,8$ & $1.714,7$ & 23,3 & $1.688,2$ & 22,9 & $1.490,1$ & $1.516,6$ & $-21,3$ & $-19,9$ \\
\hline & & & 26,1 & $1.921,4$ & $1.714,7$ & 23,3 & $1.688,2$ & 22,9 & 206,7 & 233,2 & $-53,1$ & $-47,0$ \\
\hline \multirow{3}{*}{280.000} & & & 54,5 & $3.997,6$ & $1.714,0$ & 23,4 & $1.660,3$ & 22,6 & $2.283,5$ & $2.337,3$ & $-18,5$ & $-16,6$ \\
\hline & 4.403 & 73,4 & 43,6 & $3.196,1$ & $1.714,0$ & 23,4 & $1.660,3$ & 22,6 & $1.482,1$ & $1.535,9$ & $-21,7$ & $-18,9$ \\
\hline & & & 26,1 & $1.916,2$ & $1.714,0$ & 23,4 & $1.660,3$ & 22,6 & 202,2 & 256,0 & $-54,1$ & $-41,9$ \\
\hline \multirow{3}{*}{220.000} & & & 54,5 & $3.665,8$ & $1.702,0$ & 25,3 & $1.620,9$ & 24,1 & $1.963,9$ & 2.0 & $-29,9$ & $-27,0$ \\
\hline & 4.038 & 67,3 & 43,6 & $2.930,9$ & $1.702,0$ & 25,3 & $1.620,9$ & 24,1 & $1.228,9$ & $1.310,0$ & $-35,1$ & $-30,8$ \\
\hline & & & 26,1 & $1.757,2$ & $1.702,0$ & 25,3 & $1.620,9$ & 24,1 & 55,2 & 136,3 & $-87,5$ & $-69,1$ \\
\hline \multirow{3}{*}{160.000} & & & 54,5 & $3.579,8$ & $1.698,6$ & 25,9 & $1.590,8$ & 24,2 & $1.881,1$ & $1.989,0$ & $-32,9$ & $-29,0$ \\
\hline & 3.943 & 65,7 & 43,6 & $2.862,1$ & $1.698,6$ & 25,9 & $1.590,8$ & 24,2 & 1163,5 & $1.271,3$ & $-38,5$ & $-32,8$ \\
\hline & & & 26,1 & $1.715,9$ & $1.698,6$ & 25,9 & $1.590,8$ & 24,2 & 17,3 & 125,2 & $-96,1$ & $-71,6$ \\
\hline
\end{tabular}

* IEA/maio 2012; ${ }^{* *} \mid \mathrm{EA} /$ média de 5 anos; ${ }^{* * *}$ Mínimo CONAB; ${ }^{1}$ Mesma quantidade inicial de sementes (Adversidade); ${ }^{2}$ Quantidade inicial de sementes diferente (Redução programada); ${ }^{3}$ Refere-se à variação percentual em relação ao maior REL na cultivar (população de $400.000 \mathrm{pl} \mathrm{ha}^{-1}$ ). 
Tabela 3 - Produtividade de grãos, preço real (PR), receita bruta (RB), custo operacional total (COT), retorno econômico líquido (REL) e variação percentual $(\mathrm{V})$ da soja cultivar M-SOY 8001 por população de plantas com 0 uso de herbicidas (A) e sem o controle de plantas daninhas (B). Jaboticabal-SP. Dados econômicos de 2012. Grain yield, real price (PR), gross revenue (RB), total operating cost (TOC), net economic returns (REL) and percentage variation (V) of soybean M-SOY 8001 cultivar according to the plant population using herbicides $(A)$ and without weed control $(B)$. Jaboticabal / SP. Economic data of 2012.

\begin{tabular}{|c|c|c|c|c|c|c|c|c|c|c|c|c|}
\hline \multirow{2}{*}{ População } & \multicolumn{2}{|c|}{ Produtividade } & \multirow{2}{*}{$\frac{\mathrm{PR}}{\left(\mathrm{R} \$ \mathrm{sc}^{-1}\right)}$} & \multirow{2}{*}{$\frac{\mathrm{RB}}{\left(\mathrm{R} \$ \mathrm{ha}^{-1}\right)}$} & \multicolumn{2}{|c|}{${ }^{1} \mathrm{COT}$} & \multicolumn{2}{|c|}{${ }^{2} \mathrm{COT}$} & ${ }^{1} \mathrm{REL}$ & ${ }^{2} \mathrm{REL}$ & ${ }^{1,3} \mathrm{~V}$ & $2,3 \mathrm{~V}$ \\
\hline & $\left(\mathrm{kg} \mathrm{ha}^{-1}\right)$ & $\left(\mathrm{sc} \mathrm{h}^{-1}\right)$ & & & $\left(\mathrm{R} \$ \mathrm{~h}^{-1}\right)$ & $\left(R \$ s c^{-1}\right)$ & $\left(\mathrm{R} \$ \mathrm{ha}^{-1}\right)$ & $\left(\mathrm{R} \$ \mathrm{sc}^{-1}\right)$ & \multicolumn{2}{|c|}{$\left(\mathrm{R} \$ \mathrm{ha}^{-1}\right)$} & \multicolumn{2}{|c|}{$(\%)$} \\
\hline \multicolumn{13}{|c|}{ (A) M-SOY 8001 - Com uso de herbicidas } \\
\hline & & & $54,5^{*}$ & $4.027,5$ & $1.904,3$ & 25,8 & $1.904,3$ & 25,8 & $2.123,2$ & $2.123,2$ & 0,0 & 0,0 \\
\hline \multirow[t]{3}{*}{400.000} & 4.436 & 73,9 & $43,6^{\star *}$ & $3.220,1$ & $1.904,3$ & 25,8 & $1.904,3$ & 25,8 & $1.315,8$ & $1.315,8$ & 0,0 & 0,0 \\
\hline & & & $26,1^{\star \star \star}$ & $1.930,6$ & 1.9043 & 25,8 & $1.904,3$ & 25,8 & 26,3 & 26,3 & 0,0 & 0,0 \\
\hline & & & 54,5 & $3.571,6$ & $1.887,2$ & 28,8 & $1.867,6$ & 28,5 & $1.684,4$ & $1.704,0$ & $-20,7$ & $-19,8$ \\
\hline \multirow[t]{3}{*}{340.000} & 3.934 & 65,6 & 43,6 & $2.855,6$ & $1.887,2$ & 28,8 & $1.867,6$ & 28,5 & 968,4 & 987,9 & $-26,4$ & $-24,9$ \\
\hline & & & 26,1 & $1.712,0$ & $1.887,2$ & 28,8 & $1.867,6$ & 28,5 & $-175,2$ & $-155,6$ & $-765,9$ & $-691,6$ \\
\hline & & & 54,5 & $3.779,7$ & $1.894,9$ & 27,3 & $1.855,8$ & 26,7 & $1.884,8$ & $1.923,9$ & $-11,2$ & $-9,4$ \\
\hline \multirow[t]{3}{*}{280.000} & 4.164 & 69,4 & 43,6 & $3.021,9$ & $1.894,9$ & 27,3 & $1.855,8$ & 26,7 & $1.127,0$ & $1.166,1$ & $-14,4$ & $-11,4$ \\
\hline & & & 26,1 & $1.811,8$ & $1.894,9$ & 27,3 & $1.855,8$ & 26,7 & $-83,1$ & $-44,0$ & $-416,0$ & $-267,3$ \\
\hline & & & 54,5 & $3.217,5$ & $1.874,1$ & 31,7 & $1.815,5$ & 30,7 & $1.343,4$ & $1.402,1$ & $-36,7$ & $-34,0$ \\
\hline \multirow[t]{3}{*}{220.000} & 3.544 & 59,1 & 43,6 & $2.572,5$ & $1.874,1$ & 31,7 & $1.815,5$ & 30,7 & 698,4 & 757,0 & $-46,9$ & $-42,5$ \\
\hline & & & 26,1 & $1.542,3$ & $1.874,1$ & 31,7 & $1.815,5$ & 30,7 & $-331,8$ & $-273,2$ & $-1.361,4$ & $-1.138,5$ \\
\hline & & & 54,5 & $3.601,6$ & $1.888,5$ & 28,6 & $1.810,4$ & 27,4 & $1.713,0$ & $1.791,2$ & $-19,3$ & $-15,6$ \\
\hline \multirow[t]{2}{*}{160.000} & 3.967 & 66,1 & 43,6 & $2.879,5$ & $1.888,5$ & 28,6 & $1.810,4$ & 27,4 & 991,0 & $1.069,2$ & $-24,7$ & $-18,7$ \\
\hline & & & 26,1 & $1.726,4$ & $1.888,5$ & 28,6 & $1.810,4$ & 27,4 & $-162,1$ & $-84,0$ & $-616,4$ & $-419,2$ \\
\hline
\end{tabular}

(B) M-SOY 8001 - Sem controle de plantas daninhas

\begin{tabular}{|c|c|c|c|c|c|c|c|c|c|c|c|c|}
\hline & & & 54,5 & $3.529,7$ & $1.647,5$ & 25,4 & $1.647,5$ & 25,4 & $1.882,1$ & $1.882,1$ & 0,0 & 0,0 \\
\hline \multirow[t]{3}{*}{400.000} & 3.888 & 64,8 & 43,6 & $2.822,0$ & $1.647,5$ & 25,4 & $1.647,5$ & 25,4 & $1.174,5$ & $1.174,5$ & 0,0 & 0,0 \\
\hline & & & 26,1 & $1.691,9$ & $1.647,5$ & 25,4 & $1.647,5$ & 25,4 & 44,4 & 44,4 & 0,0 & 0,0 \\
\hline & & & 54,5 & $3.294,9$ & $1.638,8$ & 27,1 & $1.619,3$ & 26,8 & $1.656,1$ & $1.675,6$ & $-12,0$ & $-11,0$ \\
\hline \multirow[t]{3}{*}{340.000} & 3.629 & 60,5 & 43,6 & $2.634,3$ & $1.638,8$ & 27,1 & $1.619,3$ & 26,8 & 995,5 & $1.015,1$ & $-15,2$ & $-13,6$ \\
\hline & & & 26,1 & $1.579,4$ & $1.638,8$ & 27,1 & $1.619,3$ & 26,8 & $-59,4$ & $-39,9$ & $-233,9$ & $-189,8$ \\
\hline & & & 54,5 & $3.337,9$ & $1.640,5$ & 26,8 & $1.601,4$ & 26,1 & $1.697,4$ & $1.736,5$ & $-9,8$ & $-7,7$ \\
\hline \multirow[t]{3}{*}{280.000} & 3.677 & 61,3 & 43,6 & $2.668,7$ & $1.640,5$ & 26,8 & $1.601,4$ & 26,1 & $1.028,2$ & $1.067,4$ & $-12,5$ & $-9,1$ \\
\hline & & & 26,1 & $1.600,0$ & $1.640,5$ & 26,8 & $1.601,4$ & 26,1 & $-40,5$ & $-1,4$ & $-191,2$ & $-103,1$ \\
\hline & & & 54,5 & $3.119,5$ & $1.632,5$ & 28,5 & $1.573,8$ & 27,5 & $1.487,0$ & $1.545,7$ & $-21,0$ & $-17,9$ \\
\hline \multirow[t]{3}{*}{220.000} & 3.436 & 57,3 & 43,6 & $2.494,1$ & $1.632,5$ & 28,5 & $1.573,8$ & 27,5 & 861,7 & 920,3 & $-26,6$ & $-21,6$ \\
\hline & & & 26,1 & $1.495,3$ & $1.632,5$ & 28,5 & $1.573,8$ & 27,5 & $-137,1$ & $-78,5$ & $-408,9$ & $-276,8$ \\
\hline & & & 54,5 & $2.981,1$ & $1.627,1$ & 29,7 & $1.548,9$ & 28,3 & $1.354,0$ & $1.432,2$ & $-28,1$ & $-23,9$ \\
\hline \multirow[t]{2}{*}{160.000} & 3.284 & 54,7 & 43,6 & $2.383,5$ & $1.627,1$ & 29,7 & $1.548,9$ & 28,3 & 756,4 & 834,6 & $-35,6$ & $-28,9$ \\
\hline & & & 26,1 & $1.429,0$ & $1.627,1$ & 29,7 & $1.548,9$ & 28,3 & $-198,1$ & $-119,9$ & $-546,2$ & $-370,1$ \\
\hline
\end{tabular}

ॠIEA/maio 2012; ${ }^{* \star} \mathrm{IEA} /$ média de 5 anos; ${ }^{* \star *}$ Mínimo CONAB; 'Mesma quantidade inicial de sementes (Adversidade); ${ }^{2}$ Quantidade inicial de sementes diferente (Redução programada); ${ }^{3}$ Refere-se à variação percentual em relação ao maior REL líquido na cultivar (população de $400.000 \mathrm{pl} \mathrm{ha}^{-1}$ ).

Os valores do REL, decorrentes fundamentalmente de variação da quantidade de sementes (Adversidade) e da mesma quantidade de sementes (Redução programada), encontramse nas Tabelas 2 e 3 . De forma geral, em todas as populações e nas duas cultivares, o controle 
de plantas daninhas resultou em maior REL do que o manejo sem o uso de herbicidas. $O$ maior REL líquido por hectare, nas duas situações estudadas, foi obtido pela cv. BRSMG 68 Vencedora, na população de $400.000 \mathrm{pl} \mathrm{ha}^{-1}$ e com o controle de plantas daninhas $(\mathrm{R} \$ 2.816,09$ preço da soja em maio/2012 do IEA).

Em termos de perdas de receita (V\%), na comparação das populações com a de $400.000 \mathrm{pl} \mathrm{ha}^{-1}$ e com o preço da saca de soja de $\mathrm{R} \$ 43,55$, em áreas com o uso de herbicidas, a maior perda ocorreu com a população de $340.000 \mathrm{pl} \mathrm{ha}^{-1}$ para a cv. BRSMG 68 Vencedora $(19,52 \%$ na Adversidade e $18,09 \%$ na Redução programada) e na de $220.000 \mathrm{pl} \mathrm{ha}^{-1}$ para a cv. M-SOY 8001 (46,92\% na Adversidade e 42,47\% na Redução programada). Em áreas sem controle de plantas daninhas, na população de $160.000 \mathrm{pl} \mathrm{ha}^{-1}$, ocorreram as maiores perdas: $38,5 \%$ e $32,8 \%$ para a cv. BRSMG 68 Vencedora e $35,60 \%$ e $28,94 \%$ para a cV. M-SOY 8001 na Adversidade e na Redução programada, respectivamente (Tabelas 2 e 3).

Assim, para mesma cultivar e manejo, as maiores perdas (V\%) podem ser esperadas quando a população de $400.000 \mathrm{pl} \mathrm{ha}^{-1}$ deixa de ser alcançada em decorrência de fatores ambientais desfavoráveis (Adversidade), já que maior custo de produção resulta em menor REL. Ou seja, reduções na população, programadas ou não, em locais que apresentam temperaturas elevadas, como é o caso de Jaboticabal-SP, acarretarão perdas de rentabilidade ao agricultor, resultados estes que, portanto, não corroboram as indicações recentes presentes na literatura de que populações de $300.000 \mathrm{pl} \mathrm{ha}^{-1}$, ou menos, seriam, de maneira geral, as mais adequadas para o cultivo de soja.

Além disso, decréscimos na população de plantas resultaram em maiores reduções no REL quando não se empregaram herbicidas para o controle de plantas daninhas. Essas reduções foram maiores quando as reduções na população de plantas foram consequências de fatores ambientais adversos.

\section{Avaliação benefício-custo das melhores opções econômicas}

A primeira opção analisada foi a substituição da cv. M-SOY 8001 pela cv. BRSMG 68 Vencedora na população de $400.000 \mathrm{pl} \mathrm{ha}^{-1}$, em áreas com o uso de herbicidas (Tabela 4). Este seria indicado por proporcionar retornos adicionais de $R \$ 538,33$ ha $^{-1}$ e a relação benefício-custo foi de $10,35 \%$. A segunda opção foi a de manter a mesma substituição de cultivares, porém em área sem o controle de plantas daninhas. Neste caso, o retorno adicional foi maior de $\mathrm{R} \$ 718,29 \mathrm{ha}^{-1}$, isto é, $15,77 \%$ acima dos custos. Estes resultados expressam, monetariamente, a maior adaptação da cv. BRSMG 68 Vencedora às condições edafoclimáticas de Jaboticabal. Nas opções 3 e 4, foi avaliada a substituição do manejo sem controle de plantas daninhas, pelo controle com o uso de herbicidas, nas duas cultivares. Quando a substituição ocorre na cv. BRSMG 68 Vencedora, houve perda de receita de $\mathrm{R} \$ 38,65 \mathrm{ha}^{-1}$. No entanto, na cv. M-SOY 8001, gerou-se um ganho de $R \$ 141,31 \mathrm{ha}^{-1}$.

De todas as opções avaliadas, o maior retorno adicional foi obtido pela alteração da cv. MSOY 8001 pela BRSMG 68 Vencedora em áreas sem controle de plantas daninhas $\left(\mathrm{R} \$ 718,29 \mathrm{ha}^{-1}\right.$ - opção 2).

As vantagens econômicas do manejo sem controle de plantas daninhas em áreas semeadas com a cv. BRSMG 68 Vencedora ocorreram devido a vários fatores, como as condições edafoclimáticas do local e das características da cultivar. Note-se que a opção 2 superou a opção 5 (retorno adicional de $\mathrm{R} \$ 576,99 \mathrm{ha}^{-1}$ ) que comparou os melhores resultados econômicos obtidos neste estudo.

A análise econômica revelou que o REL teve forte relação positiva com a produtividade. Nos casos estudados, a população de $400.000 \mathrm{pl} \mathrm{ha}^{-1}$, para as duas cultivares de soja, foi a responsável pelas maiores produtividades, de forma que decréscimo na população levou, invariavelmente, a perdas de receita. Portanto, diminuições na população ocasionadas por fatores ambientais adversos ou programadas são prejudiciais ao desempenho econômico da atividade, na região de Jaboticabal-SP.

A escolha da cultivar também é fator essencial para um maior retorno econômico. A cv. BRSMG 68 Vencedora, em condições edafoclimáticas favoráveis, superou em todas as situações estudadas a M-SOY 8001 e mostrou que pode ser empregada com sucesso em áreas em que se deseja trabalhar sem controle de plantas daninhas. $O$ uso de elevadas populações dessa cultivar, em locais com as características da área estudada, reduz o custo operacional e leva a um maior REL. Já a cv. M-SOY 8001 não se mostrou apropriada à ausência de controle de plantas daninhas. Em competição com plantas daninhas, teve sua produtividade reduzida, o que comprometeu o REL, mesmo havendo decréscimo no custo por não se usar herbicidas.

\section{Conclusões}

A maximização do retorno econômico líquido da produção de grãos de soja só aconteceu com a população de $400.000 \mathrm{pl} \mathrm{ha}^{-1} \mathrm{em}$ Jaboticabal-SP, independentemente da cultivar e do manejo de plantas daninhas adotado.

A cultivar BRSMG 68 Vencedora, de crescimento vegetativo vigoroso, permite a maximização do retorno econômico quando não se efetua o controle químico das plantas daninhas. 
Tabela 4 - Análise comparativa dos melhores resultados econômicos das cultivares e dos manejos de plantas daninhas. Jaboticabal-SP. Dados econômicos de 2012. Comparative analysis of the best economic results of the cultivars and weed management. Jaboticabal / SP. Economic data of 2012.

\begin{tabular}{|c|c|c|c|c|}
\hline \multirow{2}{*}{ OPÇÕES } & \multicolumn{4}{|c|}{ Resultados econômicos } \\
\hline & \multicolumn{2}{|l|}{ Benefícios (B) $R \$ h^{-1}$} & \multicolumn{2}{|l|}{ Custos (C) $R \$ h^{-1}$} \\
\hline 1) Substituição da cv. M-SOY & Receita bruta Vencedora & $3.836,3$ & Custo Vencedora & $1.982,2$ \\
\hline pela Vencedora. População de & Custo evitado M-SOY & $1.904,3$ & Receita não obtida M-SOY & $3.220,1$ \\
\hline $400.000 \mathrm{pl} \mathrm{ha}^{-1}$ e uso de & Total benefício-bruto & $5.740,6$ & Total Custo & $5.202,3$ \\
\hline \multirow[t]{2}{*}{ Herbicidas } & \multicolumn{2}{|c|}{ Retorno adicional (B-C) $\mathrm{R} \$$ ha $^{-1}$} & \multicolumn{2}{|l|}{538,3} \\
\hline & \multicolumn{2}{|l|}{ Relação benefício/custo } & \multicolumn{2}{|l|}{$10,35 \%$} \\
\hline 2) Substituição da cv. M-SOY & Receita bruta Vencedora & $3.626,8$ & Custo Vencedora & $1.734,0$ \\
\hline pela Vencedora. População de & Custo evitado M-SOY & $1.647,5$ & Receita não obtida M-SOY & $2.822,0$ \\
\hline $400.000 \mathrm{pl} \mathrm{ha}^{-1}$ sem o & Total benefício bruto & $5.274,4$ & Total Custo & $4.556,1$ \\
\hline \multirow[t]{2}{*}{ controle de plantas daninhas } & \multicolumn{2}{|c|}{ Retorno adicional (B-C) $\mathrm{R} \$ \mathrm{ha}^{-1}$} & \multicolumn{2}{|l|}{718,29} \\
\hline & \multicolumn{2}{|l|}{ Relação benefício/custo } & \multicolumn{2}{|l|}{$15,77 \%$} \\
\hline 3) Substituição do manejo sem & Rec. bruta ( $\mathrm{CH}$-Vencedora) & $3.836,3$ & Custo (CH - Vencedora) & $1.982,2$ \\
\hline controle de daninhas (SC) por & Custo evitado (SC) & $1.734,0$ & Receita não obtida (SC) & $3.626,8$ \\
\hline controle com herbicidas $(\mathrm{CH})$ & Total benefício-bruto & $5.570,4$ & Total Custo & $5.609,0$ \\
\hline \multicolumn{5}{|l|}{ na cv. Vencedora e população } \\
\hline \multirow[t]{2}{*}{ de $400.000 \mathrm{pl} \mathrm{ha}^{-1}$} & \multicolumn{2}{|c|}{ Retorno adicional (B-C) $\mathrm{R} \$ \mathrm{ha}^{-1}$} & \multicolumn{2}{|l|}{$-38,65$} \\
\hline & \multicolumn{2}{|l|}{ Relação benefício/custo } & \multicolumn{2}{|l|}{$-0,69 \%$} \\
\hline 4) Substituição do manejo sem & Receita bruta (CH - M-SOY) & $3.220,1$ & Custo (CH - M-SOY) & $1.904,3$ \\
\hline controle de daninhas (SC) por & Custo evitado (SC) & $1.647,5$ & Receita não obtida (SC) & $2.822,0$ \\
\hline controle com herbicidas $(\mathrm{CH})$ & Total benefício-bruto & $4.867,6$ & Total Custo & $4.726,3$ \\
\hline \multicolumn{5}{|l|}{ na cv. M-SOY e população de } \\
\hline \multirow[t]{2}{*}{$400.000 \mathrm{pl} \mathrm{ha}^{-1}$} & \multicolumn{2}{|c|}{ Retorno adicional (B-C) $\mathrm{R} \$ \mathrm{ha}^{-1}$} & \multicolumn{2}{|l|}{141,31} \\
\hline & \multicolumn{2}{|l|}{ Relação benefício/custo } & \multicolumn{2}{|l|}{$2,99 \%$} \\
\hline \multirow{3}{*}{$\begin{array}{l}\text { 5) Substituição da cv. M-SOY na } \\
\text { população de } 400.000 \text { pl ha }^{-1} \\
\text { com herbicidas pela Vencedora } \\
\text { na mesma população sem o }\end{array}$} & \multicolumn{3}{|c|}{ Receita bruta (Vencedora - SC) 3.626,84 Custo (Vencedora - SC) } & $1.734,0$ \\
\hline & \multicolumn{4}{|c|}{ 1.904,27 Rec. não obtida (M-SOY CH)3.220,1 } \\
\hline & Total benefício-bruto & $5.531,11$ & Total Custo & $4.954,1$ \\
\hline \multirow[t]{2}{*}{ manejo de plantas daninhas } & \multicolumn{2}{|c|}{ Retorno adicional (B-C) $\mathrm{R} \$$ ha $^{-1}$} & \multicolumn{2}{|l|}{576,99} \\
\hline & Relação benefício/cust & & $11,65 \%$ & \\
\hline
\end{tabular}

\section{Referências}

ANDRADE, F. M.; HAMAWAKI, O. T.; REZENDE, D. F.; SOUSA, L. B. Genótipos de soja em quatro épocas de semeadura e populações de plantas, em Uberlândia-MG. Revista Verde, Mossoró, v.5, n.4, p.124-129, 2010.

CONAB - Companhia Nacional de Abastecimento. Preços mínimos. 2012. Disponível em: <http://www.conab.gov.br/>. Acesso em: 20 nov. 2012.
EMBRAPA - Empresa Brasileira de Pesquisa Agropecuária - Embrapa. Cultivares de Soja: Regiões Sul e Central do Brasil 2010/2011. Londrina: EMBRAPA SOJA, 2010. 62 p.

EMBRAPA - Empresa Brasileira de Pesquisa Agropecuária - Embrapa (2011). Tecnologias de produção de soja - Região Central do Brasil 2012 e 2013. Londrina: EMBRAPA SOJA, 2011. 261p.

FERREIRA, D. F. Sisvar: A computer statistical analysis system. Ciência e Agrotecnologia, Lavras, v.35, n.6, p.1039-1042, 2011. 
FRANÇA-NETO, J. B.; KRZYZANOWSKI; F. C.; HENNING, A. A. A importância do uso de semente de soja de alta qualidade. Informativo ABRATES, Londrina, v.20, n.1, p.37-38, 2010.

IEA - Instituto de Economia Agrícola. Banco de dados: preços Agrícolas. 2012. Disponível em: <http://www.iea.sp.gov.br/out/bancodedados.html >. Acessado em: 20 nov. 2012.

MARTIN, N. B.; SERRA, R.; OLIVEIRA, M. D. M.; ÂNGELO, J. A.; OKAWA, H. Sistema integrado de custos agropecuários - custagri. Informações Econômicas, São Paulo, v.28, n.1, p.7-28, 1998.

MELO, H. B.; FERREIRA, L. R.; SILVA, A. A.; MIRANDA, G. V.; ROCHA, V. S.; SILVA, C. M. $M$. Interferência das plantas daninhas na cultura soja cultivada em dois espaçamentos entre linhas. Planta Daninha, Viçosa, MG, v.19, n.2, p.187-191, 2001.

REZENDE, P. M.; GRIS, C. F.; GOMES, L. L.; TOURINO, M. C. C.; BOTREL, E. P. Efeito da semeadura a lanço e da população de plantas no rendimento de grãos e outras características da soja [Glycine max (L.) Merrill]. Ciência e Agrotecnologia, Lavras, v.28, n.3, p.499-504, 2004.
SOUZA, P. I. Indicativos para obtenção de máximas produtividades na cultura da soja. Anuário ABRASEM 2013, Pelotas, p. 54-59, 2013.

TIMOSSI, P. C.; DURIGAN, J. C. Doses reduzidas de fluazifop-p-butil + fomesafen no controle de plantas daninhas na cultura de soja. Planta Daninha, Viçosa, MG, v.20, n.3, p.439-447, 2002.

TOURINO, M. C. C.; REZENDE, P. M.; SALVADOR, N. Espaçamento, densidade e uniformidade de semeadura na produtividade e características agronômicas da soja. Pesquisa Agropecuária Brasileira, Brasília, v.37, n.8, p.1071-1077, 2002. 